\title{
MICROBIAL ETIOLOGY AND ANTIBACTERIAL RESISTANCE PATTERNS OF DACRYOCYSTORHINOSTOMY CASES IN THE NORTH OF IRAN
}

\author{
SHADMAN NEMATI ${ }^{1}$, ALI MOJTAHEDI ${ }^{2 *}$, SINA MONTAZERI ${ }^{1}$, PEGAH ALIZADEH PAHLAVAN ${ }^{1}$ \\ ${ }^{1}$ Rhino-Sinus, Ear, and Skull Base Diseases Research Center, Guilan University of Medical Sciences, Rasht, Iran. ${ }^{2}$ Department of \\ Microbiology, Faculty of Medicine, Guilan University of Medical Sciences, Rasht, Iran. Email: alimojtahedi@yahoo.com
}

Received: 26 February 2018, Revised and Accepted: 18 April 2018

\section{ABSTRACT}

Objective: Nasolacrimal duct obstruction is an annoying medical condition in both ophthalmology and otolaryngology practices. As prophylactic antibiotic therapy decreases the rates of infections, understanding the prompt microbial spectrum of the pathogens has been revealed to be highly effective in such patients. We evaluated the microbial growth and bacterial resistance patterns of Bodkin tube samples obtained from patients who underwent dacryocystorhinostomy (DCR).

Methods: A total number of 72 patients were enrolled in the study, and their Bodkin tube samples were cultured 8-12 weeks after DCR at Amir-Al Momenin University Hospital of Rasht, in the north of Iran.

Results: Staphylococcus epidermidis and Aspergillus fumigatus were the most common bacterial and fungal species derived from the cultures, and $23.6 \%$ and $36.1 \%$ of the patients had neither bacterial nor fungal growth, respectively. The highest antibiotic resistance rates were toward cefazolin and cloxacillin among all the studied antibiotics.

Conclusion: Majority of cases had positive bacterial or fungal growth in their samples. Considering microbial resistance, proper antibiotic selection is recommended for the patients undergoing DCR.

Keywords: Antibiotic resistance, Bodkin tube, Dacryocystorhinostomy.

(c) 2018 The Authors. Published by Innovare Academic Sciences Pvt Ltd. This is an open access article under the CC BY license (http://creativecommons. org/licenses/by/4. 0/) DOI: http://dx.doi.org/10.22159/ajpcr.2018.v11i7.25477

\section{INTRODUCTION}

Ophthalmic infections can cause serious damage to structures of the eye, which mostly can cause by fungal or bacterial contamination [1]. The common ocular infections caused by microorganisms include conjunctivitis, keratitis, cellulitis, endophthalmitis, and dacryocystitis [1,2]. Nasolacrimal duct obstruction (NLDO) is originated from either primary etiologies (i.e. idiopathic inflammatory diseases) or secondary pathological conditions such as traumatic disruptions or infections of the eyes or nose [3-6]. The scar tissue formation is always considered annoying for patients with NLDOs, leading to epiphora or purulent discharges. Inflammation, as the main cause of obstruction, could facilitate the accumulation of infections in lacrimal sacs, causing chronic dacryocystitis. This is a common unilateral or bilateral ocular complication of NLDO, manifested by excessive tearing and occasional swelling of lacrimal sacs [7-11].

Dacryocystorhinostomy (DCR) is the gold standard therapeutic procedure for nasolacrimal obstructions. This method could be performed either externally or endonasally using nasal endoscopes (EDCR) [10-12]. DCR generally helps with the drainage of swollen sacs by bypassing the obstructed sites and connecting the nasolacrimal sacs directly to the nose. Facial scars, internal cantus injuries, and nasal cerebrospinal fluid leaks are the possible complications of DCR [12-16]. However, surgical failure due to post-surgical granuloma formation is another major concern. This complication often results from irritations or infections of silicon tubes, applied during the procedure [16-19].

As prophylactic antibiotic therapy decreases the rates of infection, understanding the prompt microbial spectrum of the pathogens has been revealed to be highly effective in such patients [17-21]. In this study, we aimed to investigate the microbial species isolated from
Bodkin tube samples of patients and also determine their antibiotic resistance patterns in a university hospital in the north of Iran.

\section{METHODS}

All patients diagnosed with acquired or primary NLDO who underwent external or endoscopic DCR with silicon tube (Bodkin tube) insertion were enrolled in the study from minimum of 6 weeks to maximum of 6 months after their operations. The study was carried out from January 2014 to April 2015. The study protocol was approved by the Ethical Committee of Guilan University of Medical Sciences. A written informed consent was obtained from the subjects, following a thorough oral explanation about the research and based on the consent forms available at www.gums.ac.ir. Moreover, all the data remained completely confidential, and results were reported as overall statistics and not applying to any specific individuals.

Patients with diabetes mellitus, immune-compromised patients, and patients who used immunosuppressant medications and also the ones who used topical or systemic antibiotics during the past months were excluded from the study. A total number of 72 patients finally participated in the study with systemic random sampling method.

All patients underwent a physical examination before the surgery by an ophthalmologist including thorough ophthalmic and lacrimal system examinations. Chronic dacryocystitis was defined as purulent discharges from the eyes' punctum lasting for more than 3 months. Furthermore, excretion of purulent discharge from lacrimal punctum following a pressure on the sac area by finger manipulation was considered as positive regurgitation test, indicating NLDO. The patients were categorized into two groups, based on their ophthalmic examination with irrigation and probing, as (1) common lacrimal canaliculus obstruction and (2) NLDO. 
Patients underwent DCR (either external or endoscopic) by two attendant surgeons (S.N. and A.H.) in similar conditions and with Bodkin tube insertion. Following DCR, the patients were visited for nasal examinations and possible debridement. These patients were followed and visited frequently every month, with their Bodkin tubes being removed 2-3 months after surgery. Before the removal of the tubes, a complete ophthalmic examination with slit lamp was performed to rule out any signs and symptoms of inflammation and possible purulent discharges for each patient. The tubes were then removed through the nasal cavity by endoscope following incising the tube loop between the superior and inferior punctum. Then, the parts of the tubes remaining in the canals (and not the nasal parts) were used as samples and transported to Stuart medium and Sabouraud dextrose agar media. These samples were immediately carried to the referral laboratory for microbiological cultures.

In the laboratory, Gram staining was performed for all the collected samples. Then, the samples were labeled and cultured on blood agar, MacConkey agar, and Chocolate agar for isolation of studied aerobes or facultative anaerobes bacteria and in thioglycollate broth for anaerobic species isolation. All media were incubated for 2 days at $37^{\circ} \mathrm{C}$ and antibiotic resistance patterns were also evaluated for the samples. For the differentiation of fungal isolations, the samples were cultured in a Sabouraud dextrose agar medium, containing chloramphenicol, for 2 weeks.

Then, antibiogram test was used to determine the antibiotic resistance patterns of all bacterial isolates using disk diffusion method recommended by the Clinical and Laboratory Standards Institute (CLSI) guideline for the following antibiotics [22]: Cefuroxime, ciprofloxacin, ceftriaxone, co-trimoxazole, cefazolin, amoxicillin, and cloxacillin. According to the CLSI guideline, the results were categorized into three groups as resistant, intermediate, and susceptible. Finally, the characterized fungal and microbial isolates and antibiotic resistance patterns were documented, and the data were analyzed by the SPSS software version 16.

\section{RESULTS}

In this study, a total number of 72 patients including 44 females (61.1\%) and 28 males (38.9\%) who underwent external or endoscopic DCR from January 2014 to April 2015 were evaluated for possible infectious complications and microbial infections. The mean age of patients was $58.15 \pm 18.73$ years old. These patients were initially regarded as in two groups based on their ages as children/adolescents and adults (39 cases) and elderly subjects (33 cases). The frequency distribution of bacterial and fungal species isolated from the silicon tubes, 12 weeks after DCR regarding the evaluated profiles of the study, is shown in Table 1. Based on the results of the study, $23.6 \%$ and $36.1 \%$ of the patients had no bacterial and fungal growth, respectively. Negative cultures for fungal species were the main pattern among both genders (10\% and $16 \%$ in males and females, respectively). Only two patients had surgical failures which revealed Staphylococcus epidermidis as the main bacterial infection while Fusarium spp. was seen in one patient. Four patients had both the common canaliculus obstruction and NLDO in the study. The most frequent positive cultures were for S. epidermidis (7 patients) and Aspergillus fumigatus and Aspergillus niger (10 patients). There was a significant relationship between gender or age and the type of bacteria in the cultured samples, as S. epidermidis was the most common bacterial species among men (7 patients), comparing to Enterobacter aerogenes (10 patients) in women.

Based on the findings of our study, the highest absolute antibiotic resistance rates were obtained for cefazolin and cloxacillin among all the studied antibiotics in total (48 cases for each) (Table 2). Both Enterobacter and S. epidermidis were resistant to cloxacillin and cefazolin (plus ciprofloxacin for S. epidermidis) in 11 cases. Citrobacter was only susceptible to cefuroxime. Proteus and Hafnia were not susceptible to any of the studied antibiotics. All three samples of Escherichia coli were resistant to amoxicillin, ciprofloxacin, and co- trimoxazole. Gram-positive bacilli were susceptible to ciprofloxacin, co-trimoxazole, and amoxicillin. Pseudomonas species were resistant to amoxicillin and ciprofloxacin (8 cases). Modest sample size and study duration are considered as major limitations of our study comparing to other literature.

\section{DISCUSSION}

NLDO is considered as an annoying medical condition in both ophthalmology and otolaryngology practice. This condition might lead to epiphora and infections around the eyes and in the face. The best way of treating such condition is through DCR with or without silicon stent insertion. Although few studies revealed relatively significant effects of silicone tube insertion during DCR on the positive long-term outcomes among patients with NLDO [19], numerously published literature supports the fact that patients are relieved from the disease symptoms without the silicone tube administration $[10,15,17,18]$. However, differentiating the microbial etiology could help the physicians select the proper antibiotic regimen. To date, there have been very few studies focusing on antibiotic resistance patterns after EDCR, although many studies have evaluated the various microbial growth patterns. In this study, we were able to isolate various bacterial and fungal species, cultured from Bodkin tubes, retrieved following DCR surgery. Given the widespread of resistant strains in country [1,23-25], the other objective of the study was to perform a comprehensive evaluation of the antimicrobial resistance patterns among our samples.

In our study, we found the Staphylococcus species to have the highest growth rate and Gram-negative bacteria grew in 20\% of samples. Hartikaineni et al. [26] defined the most common bacterial groups involved in the lacrimal sac obstruction for 127 samples of 118 patients. Positive cultures were confirmed in $48 \%$ of the patients, with $62 \%$ being Gram-positive bacteria, and the most commonly isolated bacteria was S. epidermidis (27\%). In our study, the patients with simple lacrimal canal stenosis revealed significantly lower growth rates of Streptococcus species and Gram-negative bacterial growth rates in comparison with chronic dacryocystitis. Despite this fact, 33 patients $(45.8 \%)$ had chronic dacryocystitis in our study, with $S$. epidermidis being the dominant bacterial species (7 patients: $21.2 \%$ ), and thus, we suggest that based on the present study, chronic dacryocystitis could be a potential source of intraocular infections due to higher growth rates of S. epidermidis and E. aerogenes (20). Moreover, this finding may be because of significant biofilm-producing ability of staphylococci and their association with chronic and implanted medical devices infections [27].

Kim et al. [4] evaluated the bacterial infections from the removed silicon tubes following DCR and the clinical manifestations after the surgery related to these infections in patients with NLDO. Of 39 cultured samples from 33 patients $(87.2 \%$ external DCR and 5\% endoscopic DCR), 94.9\% were positive for various microbial species, included 73.1\% Gram-positive bacteria (73.9\%: S. epidermidis), 23.1\% Gramnegative bacteria, and 3.8\% fungal growth. In this study, we had $48.6 \%$ and $16.7 \%$ positive growth rates for various fungal and S. epidermidis, respectively. Furthermore, the results of Kim et al., like as our findings, indicated that positive bacterial cultures mostly were due to the normal flora [4].

100 samples obtained from patients with chronic dacryocystitis were assessed for possible bacterial and fungal growths in the Sun et al. study [9]. There were only eight samples positive for fungal growth, and Staphylococcus species were the most common bacteria. Furthermore, the most effective antibacterial infections were levofloxacin and ofloxacin [9].

According to the previous studies, post-surgical soft tissue infections could facilitate the open surgery of the lacrimal canal to fail eventually [14]. Based on the results of Walland and Rose retrospective study on 413 patients, the primary and secondary surgical failure rates were $12 \%$ and $8.9 \%$, respectively [14]. Final surgical failure is highly associated with the canalicular stenosis, purulent discharges during 


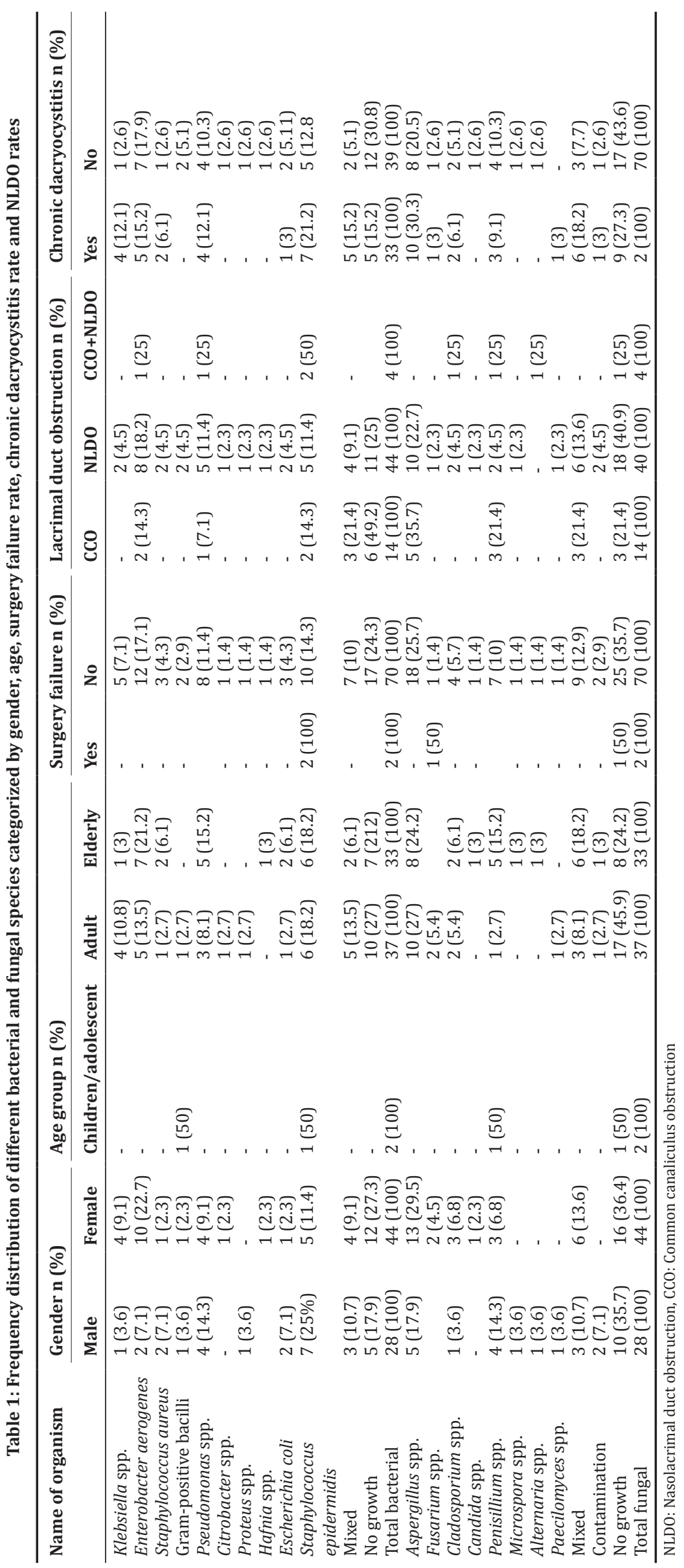




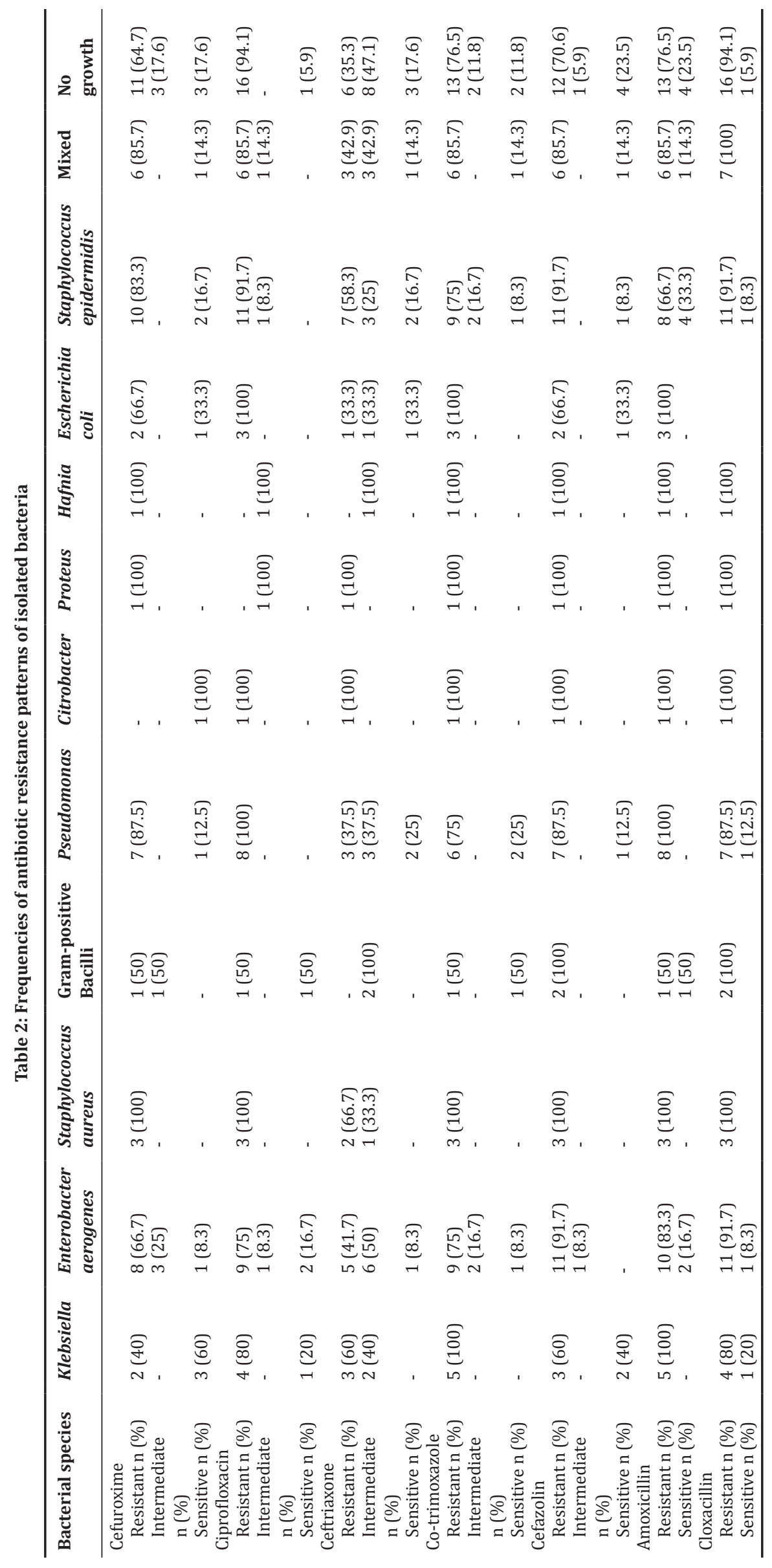


tube removal, recurrent endoscopy history, and Pseudomonas infections. Proper antibiotic regimens could significantly decline the rates of infections and obviously the rates of surgical failures. However, postsurgical antibiotic therapy for localized infections has been proven to be far less effective rather than preventive antibiotic prescriptions [14].

In another study, Nemati et al. evaluated 50 patients with chronic dacryocystitis for post-surgical infections. In that study, S. epidermidis and Candida were the most common species obtained from lacrimal sac discharge cultures. The article also suggests proper antibiotic therapy for the possible infections in patients undergoing DCR [10].

\section{CONCLUSION}

In our study, the majority of samples were positive for the growth with S. epidermidis and A. fumigatus as the most common bacterial and fungal etiology, respectively. Thus, considering microbial resistance, proper antibiotic selection is recommended for the patients undergoing DCR. We recommend further future studies based on antibiotic resistance patterns in patients similar to ours as antibiotic resistance has become a major medical concern recently.

\section{ACKNOWLEDGMENTS}

We appreciate all our colleagues for their cooperating and participating in our study, especially the staff of Rhino-Sinus Research Center at Amir-Al-Momenin University Hospital of Rasht. This work was funded by Guilan University of Medical Sciences with a grant number 1930506203.

\section{AUTHORS' CONTRIBUTION}

S Nemati, A Mojtahedi, S Montazeri, and P Alizadeh Pahlavan conceived the study and revised the manuscript. S Nemati, and A Mojtahedi participated in study design and wrote drafts of the manuscript. S Montazeri conceived the study and carried out the statistical analysis. S Nemati and A Mojtahedi participated in revision manuscript. All authors read and approved the final manuscript.

\section{CONFLICTS OF INTEREST}

The authors have none to declare.

\section{REFERENCES}

1. Subramanian A, Yessaian S. Screening and antibiogram pattern of bacterial ophthalmic infections. Int J Pharm Pharm Sci 2015;7:412-5.

2. Murugan N, Malathi J, Therese KL, Madhavan HN. Antimicrobial susceptibility and prevalence of extended spectrum betalactamase (ESBL) and metallo betalactamase (MBL) and its co-existence among Pseudomonas aeruginosa recovered from ocular infections. Int J Pharm Pharm Sci 2015;7:147-51.

3. Ali MJ, Manderwad G, Naik MN. The microbiological spectrum and antibiotic sensitivity profile of extubated silicone stents following dacryocystorhinostomy. Orbit 2013;32:298-303.

4. Kim SE, Lee SJ, Lee SY, Yoon JS. Clinical significance of microbial growth on the surfaces of silicone tubes removed from dacryocystorhinostomy patients. Am J Ophthalmol 2012;153:253-7.e1.

5. Savino G, Battendieri R, Traina S, Corbo G, D'Amico G, Gari M, et al. External vs. endonasal dacryocystorhinostomy: Has the current view changed? Acta Otorhinolaryngol Ital 2014;34:29-35.

6. Kamal S, Bodh SA, Goel R, Kumar S. Clinical significance of microbial growth on the surfaces of silicone tubes removed from dacryocystorhinostomy patients. Am J Ophthalmol 2012;153:189-90.

7. Carifi M, Carifi G. Clinical significance of microbial growth on the surfaces of silicone tubes removed from dacryocystorhinostomy patients. Am J Ophthalmol 2012;154:418-9.

8. Mikaniki E, Rasolinejad S. Efficacy of dacryocystorhinostomy with catheter insertion or bodkin tube in the treatment of nasolacrimal obstruction. J Babol Uni Med Sci 2007;9:37-40.

9. Sun X, Liang Q, Luo S, Wang Z, Li R, Jin X. Microbiological analysis of chronic dacryocystitis. Ophthalmic Physiol Optics 2005;25:261-3.

10. Nemati S, Nasiri M, Medghalchi A, Rouhi R. Comparison of endonasal endoscopic versus external dacryocystorhinostomy results for adult patients with acquired nasolacrimal duct obstruction. J Guilan Uni Med Sci 2014;23:66-74

11. Ojaghi H, Masoumi R, Mohammadi M. Dacryocystorhinostomy with budkin tube operation in patients with chronic dacryocystitis. J Ardabil Uni Med Sci 2008;8:7-13.

12. Chong KK, Lai FH, Ho M, LukA, Wong BW, Young A. Randomized trial on silicone intubation in endoscopic mechanical dacryocystorhinostomy (SEND) for primary nasolacrimal duct obstruction. Ophthalmology 2013;120:2139-45

13. Walland MJ, Rose GE. Factors affecting the success rate of open lacrimal surgery. Br J Ophthalmol 1994;78:888-91.

14. Walland MJ, Rose GE. Soft tissue infections after open lacrimal surgery. Ophthalmology 1994;101:608-11.

15. Parsa K, Schaudinn C, Gorur A, Sedghizadeh PP, Johnson T, Tse DT, et al. Demonstration of bacterial biofilms in culture-negative silicone stent and jones tube. Ophthal Plast Reconstr Surg 2010;26:426-30.

16. Walland MJ, Rose GE. The effect of silicone intubation on failure and infection rates after dacryocystorhinostomy. Ophthalmic Surg 1994;25:597-600.

17. Zaman M, Babar TF, Abdullah A. Prospective randomized comparison of dacryocystorhinostomy (DCR) with and without intubation. Pak J Med Res 2005;44:75-8.

18. Feng YF, Cai JQ, Zhang JY, Han XH. A meta-analysis of primary dacryocystorhinostomy with and without silicone intubation. Can $\mathrm{J}$ Ophthalmol 2011;46:521-7.

19. Choung HK, Khwarg SI. Selective non-intubation of a silicone tube in external dacryocystorhinostomy. Acta Ophthalmol Scand 2007;85:329-32.

20. Pandya VB, Lee S, Benger R, Danks JJ, Kourt G, Martin PA, et al. External dacryocystorhinostomy: Assessing factors that influence outcome. Orbit 2010;29:291-7.

21. Vicinanzo MG, McGwin G, Boyle M, Long JA. The consequence of premature silicone stent loss after external dacryocystorhinostomy. Ophthalmology 2008;115:1241-4.

22. Wayne P. Performance Standards for Antimicrobial Susceptibility Testing. Clinical and Laboratory Standards Institute (CLSI). $25^{\text {th }}$ Informational Supplement; 2015;M100-S25.

23. Haghighatpanah M, Nejad AS, Mojtahedi A, Amirmozafari N, Zeighami H. Detection of extended-spectrum beta-lactamase (ESBL) and plasmid-borne blaCTX-M and blaTEM genes among clinical strains of Escherichia coli isolated from patients in the north of Iran. J Glob Antimicrob Resist 2016;7:110-3.

24. Tavakoly T, Jamali S, Mojtahedi A, Mirzaei MK, Shenagari M. The prevalence of CMY-2, OXA-48 and KPC-2 genes in clinical isolates of Klebsiella spp. Cell Mol Biol (Noisy-le-grand) 2018;64:40-4.

25. Khashei R, Sarie HS, Alfatemi MH, Zomorodian K. Antimicrobial resistance patterns of colonizing microflora on the personnel hands and noses working in the neonatal intensive care unit (NICU). World Appl Sci J 2014;30:1232-7.

26. Hartikainen J, Lehtonen OP, Saari KM. Bacteriology of lacrimal duct obstruction in adults. Br J Ophthalmol 1997;81:37-40.

27. Zalipour M, Ebrahim-Saraie HS, Sarvari J, Khashei R. Detection of biofilm production capability and icaA/D genes among staphylococci isolates from Shiraz, Iran. Jundishapur J Microbiol 2016;9:e41431. 